\title{
Effect of Salinity on the Antiparasitic Activity of Hyssop Essential Oil
}

Nesrine Ben Hamida ${ }^{a}$, Rafael A. Martínez-Díaz ${ }^{d}$, Hela Mahmoudia ${ }^{a}$ Kamel Msaada ${ }^{b}$, Zeineb Ouerghi $^{\mathrm{a}}$, Maria Fe Andres ${ }^{\mathrm{c}}$, Azucena González-Coloma ${ }^{\mathrm{c}^{*}}$

${ }^{a}$ Unité de Physiologie et de Biochimie de la Réponse des Plantes aux Contraintes Abiotiques, Faculté des Sciences de Tunis, Université de Tunis El Manar, 2092 Tunis, Tunisia;

b Laboratory of Aromatic and Medicinal Plants, Biotechnology Center in Borj-Cedria Technopole, BP. 901, Hammam-Lif 2050, Tunisia;

${ }^{c}$ Instituto de Ciencias Agrarias, Consejo Superior de Investigaciones Científicas, 28006 Madrid, Spain;

d Departamento de Medicina Preventiva, Salud Pública y Microbiología, Facultad de Medicina, Universidad Autónoma de Madrid, C/Arzobispo Morcillo S/N, 28029 Madrid, Spain.

*Corresponding author: Pr. Azucena González-Coloma Instituto de Ciencias Agrarias, Consejo Superior de Investigaciones Científicas, 28006 Madrid, Spain. Email: azu@ica.csic.es

\begin{abstract}
The present work reports the effect of salt treatment on Hyssopus officinalis growth, essential oil (EO) yield and composition and the antiparasitic effects of the oil against plant (Phytomonas davidi and Meloidogyne javanica) and human (Trypanosoma cruzi) parasites. The plants were grown in hydroponics and treated with different $\mathrm{NaCl}$ concentrations $(0,50$, 75 , and $100 \mathrm{mM} \mathrm{NaCl}$ ).

Our results showed that salinity decreased plant growth and EO yield of hydroponically cultivated plants of $H$. officinalis with increasing $\mathrm{NaCl}$ levels. Salinity also induced changes in the chemical composition of treated hyssop EOs, decreasing the monoterpene and increasing the sesquiterpene groups. The oxygenated monoterpenes, represented primarily by isopinocamphone and pinocarvone, were the major chemical class. The EOs from treated $H$. officinalis showed moderate antiparasitic effects against $T$. cruzi, independent of the salt treatment, and stronger salt-dependent effects on $P$. davidi, with the $50 \mathrm{mM} \mathrm{NaCl}$ treatment resulting in the strongest phytomonacidal effect. The hyssop EOs tested here were strong nematicidal agents against $M$. javanica, these effects being also stronger for the $50 \mathrm{mM} \mathrm{NaCl}$ treatment. Therefore, a moderate salt treatment $(50 \mathrm{mM} \mathrm{NaCl})$ reduced plant growth and $\mathrm{EO}$ yield but increased its biocidal effects on plant parasites (P. davidi and M. javanica).
\end{abstract}

KEYWORDS: Hyssop (Hyssopus officinalis L.); Salt stress; Essential oil; Trypanosoma cruzi; Phytomonas davidi; Meloidogyne javanica.

ABBREVIATIONS: AMPs (Aromatic and medicinal plants), EOs (Essential oils), WHO (World health organization), BZ (Benznidazole), NFX (Nifurtimox), GC-MS (Gas chromatography-mass spectrometry), LIT (liver infusion tryptose), FCS (fetal calf serum), GI 
(growth inhibition), PMS/MTT (phenazine methosulfate / methylthiazolyldiphenyltetrazolium bromide), RH (relative humidity), SDS (sodium dodecyl sulfate).

\section{Introduction}

Aromatic and medicinal plants (AMPs) are gaining interest due to the increasing awareness of the harm induced by synthetic chemicals to both human health and environment (1). This prompted many industries to focus on the use of plant bio products as a safe alternative to chemicals (1). Essential oils (EOs) are secondary metabolites synthesized by different organs of APMs with diverse biological activities (2). EOs are considered environmentally friendly products because of their biodegradability, strong efficiency and low level of toxicity to mammals (3). Moreover, in agriculture they can ensure the protection of plants against different diseases and pests without accumulating in the environment and with a lower risk of selection of resistant pathogen strains and pests (3).

Hyssopus officinalis (L.) (Lamiaceae) is a perennial herb of Mediterranean origin. It is a wellknown medical and culinary herb with therapeutic properties such as spasmolytic, antiviral, sudorific, emmenagogue, carminative, tonic, diuretic, expectorant, antiseptic, antibacterial, antioxidant, anti-inflammatory, cardiovascular and anthelmintic (4,5). There are numerous reports on the chemical composition of $H$. officinalis essential oil (EO), with isopinocamphone, pinocamphone, and pinenes the most characteristic constituents. However, important qualitative differences in hyssop EO composition due to geographic origin and variety have been reported (6).

Selected hyssop accessions are commercially cultivated. The crop can be productive for approximately 10 years and the plants are preferably harvested during blooming season to produce EOs by steam distillation with yields around $0.5 \%$ (6). Furthermore, this plant can grow in semi-arid climatic conditions (7). 
Drought and salinity are major environmental factors that influence crop productivity worldwide $(8,9)$. Drought and salinity stress have been shown to trigger various interacting events including the inhibition of enzyme activities in metabolic pathways $(10,11)$. Drought and saline stress cause changes in essential oil yield and quantitative or qualitative composition of aromatic plants (12, 13, 14, 15 16, 17-18), including H. officinalis (19).

The increasing demand for bio pesticides, safer antibiotics and drugs (nontoxic to humans or environment and easily biodegradable) have resulted in new medicinal and agricultural applications of hyssop EOs based on their effects on human resistant pathogenic bacteria, food-borne fungal pathogens, insect pests and phytopathogenic fungi $(6,20,21,22,23,24-$ 25). However, despite its traditional use as an anthelmintic (5), little is known on the antiparasitic effects on hyssop EO except for one record on an EO from H. officinalis grown in Spain reported as trypanocidal (26), with moderate effects on the plant parasitic nematode Meloidogyne javanica (27).

Parasites belonging to Trypanosomatidae family are agents of human, animal and plant diseases (28). The genus Phytomonas includes all trypanosomatids that parasitise plants (29). About 17 families of plants are infected by these flagellated protozoans which are transmitted through hemipteran insects. They have been detected in latex tubes of laticifers, in phloem of trees, in fruits and also in seeds (30). The most important plant diseases caused by Phytomonas are coffee phloem necrosis, oil palm marchitez and coconut hartrot (31). Currently, there are no reports on the effects of EOs or any other plant metabolite on Phytomonas. Trypanosoma cruzi is a protozoan parasite responsible of Chagas disease which is one of the most serious health problems in Latin America. This pathogenic agent is mostly transmitted to humans by triatomine insects (kissing bugs). Currently, the treatment of this disease is mainly based on two drugs: Benznidazole (BZ) and Nifurtimox (NFX) (32), 
however, both have many disadvantages (33). Therefore, the search for more safe, reliable and efficient drugs is necessary.

Root-knot nematodes (Meloidogyne spp.) are major threats to agriculture worldwide. In the last decades, environmental and human health concerns have steadily reduced the availability of efficient commercial nematicides. In this context, EOs from AMPs have been proposed as an environmentally friendly alternative to synthetic nematicidal agents (27). Given the potential applications of hyssop EO in the health and agro-food industry and the plant production constraints that saline stress can induce in commercial hyssop, in this report we examine: i) the effect of $\mathrm{NaCl}$ concentrations $(0,50,75$ and $100 \mathrm{mM})$ on $\mathrm{EO}$ yield and composition of aerial parts (stems and leaves) of Hyssopus officinalis L. plants, from a French population, during vegetative stage and ii) the antiparasitic effects of these EOs against plant (Meloidogyne javanica and Phytomonas davidi) and human (Trypanosoma cruzi) parasites.

\section{Experimental}

\section{Plant material and hydroponic cultivation}

Hyssopus officinalis L. seeds (organic products certified by ECOCERT FR-BIO-01) were provided by "Graines del Païs" (Bellegarde-du-Razès, France). First, the seeds were washed thoroughly with distilled water, then placed in Petri dishes, and finally, put for germination in the dark at $25^{\circ} \mathrm{C}$. After 7 days, in a controlled growth chamber, seedlings were transplanted into 6-L aerated pots (10 seedling per pot) containing an eightfold diluted nutrient solution of Hoagland and Arnon (34). Four weeks after transplanting, an initial harvest was performed (6 plants) and four $\mathrm{NaCl}$ concentrations were applied (0, 50, 75 and $100 \mathrm{mM} \mathrm{NaCl})$. All pots were placed under two luminous ceilings (day/night temperature $23 / 17^{\circ} \mathrm{C}$; relative humidity 80/60\%; $16 \mathrm{~h}$ photoperiod with $200-\mu \mathrm{mol} . \mathrm{m}^{-2} \mathrm{~s}^{-1}$ PAR at the plant level).

\section{Dry weight and water content}


After 14 days of treatment, a final harvest was performed and plants were collected and randomly selected (6 plants) from each treatment. Aerial plant parts (leaves and stems) were oven dried $\left(60^{\circ} \mathrm{C}, 72 \mathrm{~h}\right)$ to calculate their dry weight (DW) and water content (WC, $\mathrm{ml} \mathrm{g}^{-1}$ $\mathrm{DW})$ with the equation: $\mathrm{WC}=(\mathrm{FW}-\mathrm{DW}) / \mathrm{DW}$, where $\mathrm{FW}$ : fresh weight and $\mathrm{DW}$ : dry weight. The rest of the plants were dried at room temperature in an aerated dark environment for essential oil analysis.

\section{Sodium $\left(\mathrm{Na}^{+}\right)$and potassium $\left(\mathrm{K}^{+}\right)$analysis}

$\mathrm{Na}^{+}$and $\mathrm{K}^{+}$were extracted from $25 \mathrm{mg}$ of oven dried aerial parts using $0.5 \% \mathrm{HNO}_{3}$ and then measured by flame emission photometry (Jenway PFP7) (35).

\section{Essential oil extraction}

Air- dried aerial parts were reduced to small pieces, then subjected to hydrodistillation (40 g of each sample) using a Clevenger apparatus for 2 hours (36). The oils were dried over sodium sulfate $\left(\mathrm{Na}_{2} \mathrm{SO}_{4}\right)$ and stored in amber glass vials at $4{ }^{\circ} \mathrm{C}$ until the beginning of analyzes.

\section{Essential oil analysis}

Analysis of the studied hyssop EO was carried out using a gas chromatograph Shimadzu, GC2010 equipped with an auto sampler (auto injector AOC-20i), a FID detector and interfaced with a mass spectrometer QP2010 Ultra and a TRB-5 capillary column $(30 \mathrm{~m} \times 0.25 \mathrm{~mm} \mathrm{x}$ $0.25 \mu \mathrm{m}$ film thickness). Working conditions were as follows: split ratio (20:1), injector temperature, $300(260){ }^{\circ} \mathrm{C}$; temperature of the transfer line connected to the mass spectrometer, $220(280){ }^{\circ} \mathrm{C}$; initial column temperature $70^{\circ} \mathrm{C}$, then heated to $290(270){ }^{\circ} \mathrm{C}$ at 6 ${ }^{\circ} \mathrm{C} \min ^{-1}$ for $15 \mathrm{~min}$. Scan time and mass range were $0.2 \mathrm{~s}$ and $35-450 \mathrm{~m} / \mathrm{z}$ respectively. The chemical constituents were identified by comparing their relative retention times and mass spectra with those of Wiley 229 library data of the GC-MS system and literature data if needed (37). 


\section{In Vitro assay on Trypanosoma cruzi and Phytomonas davidi}

The Y strain of Trypanosoma cruzi was originally isolated from a human infection (38), and it has been kept in our laboratory, either in culture or frozen in liquid nitrogen (38).

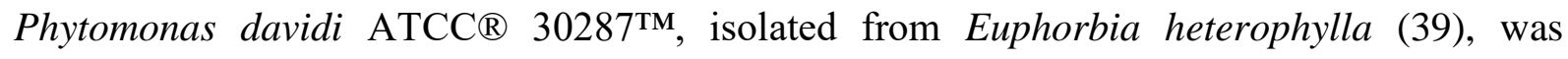
purchased from the American Type Culture Collection (39).

The bioassays were carried out with epimastigote forms of $T$. cruzi, or promastigotes of $P$. davidi cultured in LIT medium supplemented with $10 \%$ heat-inactivated foetal calf serum as described for T. cruzi (40). Parasite cultures in logarithmic growth phase $\left(8-10 \times 10^{6}\right.$ epimastigotes $/ \mathrm{mL}$ or $6-7 \times 10^{6}$ promastigotes $\left./ \mathrm{mL}\right)$ were distributed $(90 \mu \mathrm{L} /$ well $)$ in 96 -well flat-bottom plates.

EOs were tested for $72 \mathrm{~h}$ at several concentrations $(800,400,200,100,10$ and $1 \mu \mathrm{g} / \mathrm{mL})$ for T. cruzi using Nifurtimox as the reference drug. Parasite viability was analyzed by a modified MTT colorimetric assay method (40). After $72 \mathrm{~h}, 10 \mu \mathrm{L}$ MTT/PMS were added to each well and incubated for 75 min. For P. davidi, EOs were tested for $24 \mathrm{~h}$ at the same concentrations $(800,400,200,100,10$ and $1 \mu \mathrm{g} / \mathrm{mL})$. No reference drug was tested because there is no one described for it. After $24 \mathrm{~h}, 10 \mu \mathrm{L}$ MTT/menadione ( $5 \mathrm{mg} / \mathrm{mL}$ MTT, $1.6 \mathrm{mg} / \mathrm{mL}$ menadione) were added to each well and incubated for $75 \mathrm{~min}$. From here the process was the same for both parasites, $100 \mu \mathrm{L}$ sodium dodecyl sulfate (SDS) were added to dissolve formazan crystals obtained as a result of the reduction of MTT. After 15-30 min the absorbance was measured at $630 \mathrm{~nm}$. The activity was calculated as percentage growth inhibition (\%GI) as follows: $\% \mathrm{GI}=100-[(\mathrm{At}-\mathrm{Ab}) /(\mathrm{Ac}-\mathrm{Ab})] \mathrm{x} 100$, where At is the absorbance of treated wells, Ac the absorbance of control wells (not treated) and Ab the absorbance of blank wells (culture medium and vehicle only). All assays were carried out in triplicate and were repeated at least three times independently to confirm the results.

\section{In vitro nematicidal effects}


The nematodes used for the experiments came from a population of Meloidogyne javanica maintained on Solanum lycopersicum plants (var. Marmande) in pot cultures at $25{ }^{\circ} \mathrm{C}$, and $70 \%$ RH. Egg masses were handpicked from infected tomato roots and second-stage juveniles (J2) were obtained from hatched eggs by incubating handpicked egg masses in a water suspension at $25^{\circ} \mathrm{C}$ for $24 \mathrm{~h}$.

The bioassays were carried out as described by Andres et al. (27). The treatments were prepared with EOs diluted in a DMSO-Tween solution (0.5\% Tween20 in DMSO). The test solutions $(5 \mu \mathrm{L})$ were added to of 96 -well plates containing 100 nematodes in $95 \mu \mathrm{L}$ of water per well. The initial concentration tested was $1 \mathrm{mg} / \mathrm{mL}$. Four control wells with water/DMSOTween were included in each experiment. All treatments were replicated four times. The plates were covered to prevent evaporation and maintained in darkness at $25^{\circ} \mathrm{C}$. After $72 \mathrm{~h}$, the dead $\mathbf{J} 2$ were counted. The nematicidal activity is presented as percent dead $\mathbf{J} 2$ corrected according to Schneider-Orelli's formula (41).

\section{Statistics}

Data are expressed as mean \pm standard error. The means were compared using the one-way and multivariate analysis of variance (ANOVA) followed by Duncan's multiple range tests. The differences between individual means were deemed to be significant at $\mathrm{P}<0.05$. (Statistica v 5.1” software) (42).

\section{Results and discussion}

\section{Effect of salinity on aerial parts growth, water content and ion accumulation}

Our results showed that after 2 weeks, salt reduced significantly hyssop plant growth (reduction was about 41, 64 and $67 \%$, respectively, at 50, 75 and $100 \mathrm{mM} \mathrm{NaCl}$ ) (Figure1a). Additionally, $\mathrm{Na}^{+}$content increased within hyssop aerial parts along with $\mathrm{NaCl}$ doses to reach $0.288 \% \mathrm{DW}$ at $100 \mathrm{mM} \mathrm{NaCl}$ (Figure 2a). The water (Figure $1 \mathrm{~b}$ ) and $\mathrm{K}^{+}$(Figure 2b) content in the plant increased significantly with respect to the control at $50 \mathrm{mM} \mathrm{NaCl}$. Salt stress 
related reduction in plant growth has been previously reported for H. officinalis (19). Several authors noted that the salt-induced growth decrease may be linked to osmotic effects, which affect cell turgor and expansion (43). In our case, the reduction of aerial parts growth was not due to an osmotic effect since their water content was not affected under salinity (Figure 1b) suggesting therefore, that plants subjected to salt stress are able to compartmentalize excessive $\mathrm{Na}^{+}$ions into the vacuoles thus contributing to cell osmotic adjustment (44). Several authors found that $\mathrm{K}^{+}$content was higher in salt tolerant plants than in sensitive ones $(45,46)$. Furthermore, an increase in $\mathrm{K}^{+}$concentrations under high $\mathrm{NaCl}$ levels in broad bean and pea plants resulted in an increase in tissue water content (47). Therefore, the increased $\mathrm{K}^{+}$ accumulation at $50 \mathrm{mM} \mathrm{NaCl}$ could facilitate osmotic adjustment in hyssop plants.

\section{Effect of salinity on essential oil yield and composition}

The hydrodistillation of $H$. officinalis aerial parts (control) gave EO with an average yield of $0.48 \%$. The exposure of hyssop plants to increasing $\mathrm{NaCl}$ concentrations strongly decreased EO yield (reduction was about 52, 69 and 75\%, respectively, at 50, 75 and $100 \mathrm{mM} \mathrm{NaCl}$ ) (Figure 3).

Average EO yields reported for hyssop range between $0.18-2.0 \%(48,19)$. Most studies on hyssop EO yields have been carried out on flowering plants, while plants in vegetative stage have been used here. Phenological growth stage and cultivation conditions affect hyssop EO yield. For example, EO yields were the highest in flowering stage $(49,7,50)$ and increased with plant age (51), fertilization (52), irrigation (53) and temperature (54).

Contrary to our results, salt stress increased EO yield in field cultivated hyssop plants collected at flowering stage (19). However, in other aromatic species such as Melissa officinalis (55), Mentha x piperita, Mentha pulegium, M. suaveolens (56) and Carthamus tinctorius (57), EO production was also negatively affected by salt stress. Such decrease in EO content could be due to the degradation of the secretory structures following leaf necrosis 
(58). Moreover, in many Lamiaceae plants salinity reduced EO yield presumably by inhibiting the supply of cytokinin from roots to shoots and thus altering the ratio between leaf cytokinin and abscisic acid (59).

The analysis of the chemical composition of hyssop EO resulted in the identification of 18 compounds (Table 1). The major components were isopinocamphone (26.62-27.70\%), pinocarvone (12.45-15.99\%), followed by elemol (12.25-14.41\%), $\beta$-pinene $(5.07-8.16 \%)$ and germacrene D (7.22-8.12\%). Overall, these EOs were composed of oxygenated monoterpenes (40.13-44.18\%), sesquiterpene hydrocarbons (18.23-22.11\%), monoterpene hydrocarbons $(12.33-16.61 \%)$ and oxygenated sesquiterpenes $(12.25-14.41 \%)$. The chemical variations in EO composition were only quantitative. The variance analysis showed that the relative abundance of EO components was affected by salt stress $(\mathrm{P}<0.001)$ except isopinocamphone $(\mathrm{P}<0.01)$ and $\beta$-cubebene $(\mathrm{P}<0.05)$. Overall, sesquiterpenes (hydrocarbons and oxygenated) increased with salinity; in fact the increase was about $21 \%$ at $100 \mathrm{mM} \mathrm{NaCl}$ and $18 \%$ at 75 $\mathrm{mM} \mathrm{NaCl}$. However, monoterpenes (hydrocarbons and oxygenated) decreased with increasing $\mathrm{NaCl}$ levels; the reduction was about 26 and 9\%, respectively, at $100 \mathrm{mM} \mathrm{NaCl}$ (Table 1). The most characteristic constituents of $H$. officinalis EO are isopinocamphone, pinocamphone, and pinenes (6). However, other hyssop chemotypes have been described containing 1,8-cineole and $\beta$-pinene as major components $(25,60,48)$, linalool, 1,8-cineole and limonene (61, 62), linalool and methyl eugenol (63), myrtenol and $\beta$-pinene, $\beta$-pinene and 1,8-cineole (64), myrtenyl acetate and camphor (4). A similar EO composition to the one described here, with pinocarvone and pinocamphone, has been found for different accessions of H. officinalis from Turkey $(65,66)$ and Yugoslavia (67).

The reported effects of salt stress on EO quantitative composition are variable. For example, decreased monoterpenes (hydrocarbon and oxygenated) and increased sesquiterpene hydrocarbons have been reported for marjoram EO (68). In black cumin, monoterpenes 
(hydrocarbon and oxygenated) and sesquiterpene hydrocarbons increased in seed EO with saline irrigation water levels (69). Furthermore, saline water affected the quantitative composition of hyssop EO, collected at flowering stage, with cis-pinocamphone and $\beta$-pinene being the main components and increased the oxygenated monoterpenes and monoterpene hydrocarbons (at 6 and $8 \mathrm{dSm}^{-1}$ saline water treatments, respectively) (19).

\section{Effect of salinity on the antiparasitic activity of Hyssopus officinalis L. essential oil}

The in vitro antiprotozoal activity of hyssop EOs is shown in Table 2. All EOs tested were active on T. cruzi and P. davidi at $200 \mu \mathrm{g} / \mathrm{mL}(100 \%$ inhibition for 800 and $400 \mu \mathrm{g} / \mathrm{mL}$, data not shown), there was a reduction in activity at $100 \mu \mathrm{g} / \mathrm{mL}$ (43-54\% growth inhibition) for $T$. cruzi, independent of the salt treatment. In the case of $P$. davidi, the effects of hyssop EO at $100 \mu \mathrm{g} / \mathrm{mL}$ varied with the salt treatment, with the EOs from the 50 and $100 \mathrm{mM} \mathrm{NaCl}$ treatments the most active (97 and $78 \%$ inhibition, respectively), followed by the 75 and 0 $\mathrm{mM} \mathrm{NaCl}$ EOs (58 and $39 \%$ inhibition).

Guardo et al. (26) reported moderate trypanocidal effects of an $H$. officinalis EO from a Spanish hyssop population on $T$. cruzi with activity levels similar to the ones found here. However, the main EO components were 1,8-cineole and $\beta$-pinene which were not active against the parasite, suggesting synergistic effects between the EO components. This is the first report on the phytomonacidal effects of $H$. officinalis EO.

Neither of the major components of the hyssop EO, pinocarvone or isopinocamphone, described here have been reported as being trypanocidal or antiprotozoal. Among other hyssop EO components, $\alpha$-pinene showed a moderate effect on $T$. cruzi (70) and strong effect on T. brucei, while $\alpha$-phellandrene showed a moderate effect (71). $\beta$-Pinene was active against T. cruzi and showed synergistic effect with carvacrol (26). Germacrene D inhibited the enzyme cruzain, a cysteine protease from $T$. cruzi $(72,73)$ and this compound showed moderate activity against trypomastigote forms (74). Therefore, the antitrypanosmal and 
phytomonacidal effects observed for hyssop EOs could be related to the presence of these trypanocidal compounds.

Many plant essential oils are known to exhibit nematicidal effect (75). Recently, biocidal (nematicidal, ixodicidal, phytotoxic and insecticidal) activities of hyssop EOs have been reported $(76,77)$. In our study, the oils showed strong nematicidal activity that negatively correlated with saline treatment. EOs of the control and the $50 \mathrm{mM} \mathrm{NaCl}$ treatment show the most nematicidal effects at $1 \mu \mathrm{g} / \mu \mathrm{L}$ (Table 3).

Previous reports showed a low nematicidal activity for the EO of Spanish $H$. officinalis containing 1,8-cineole and $\beta$-pinene as the major components (27). Therefore, this is the first report on the nematicidal effects of hyssop EO containing pinocarvone and isopinocamphone and on the negative effect of $\mathrm{NaCl}$ treatments such an effect. Neither pinocarvone or isopinocamphone, have been reported as being nematicidal while $\beta$-pinene was inactive against $M$. javanica (27). Among other hyssop EO components, $\alpha$-pinene strongly inhibited an acetylcholinesterase from the pinewood nematode Bursaphelenchus xylophilus (78), elemol showed in vitro larvicidal effects on Anisakis simplex (79).

\section{Conclusion}

Our results showed that salt stress decreased plant growth and EO yield of hydroponically cultivated plants of $H$. officinalis. Salinity also induced quantitative changes in the chemical composition of treated hyssop EOs, decreasing the monoterpene and increasing the sesquiterpene groups. The oxygenated monoterpenes, represented primarily by isopinocamphone and pinocarvone, were the major chemical class. The EOs from treated $H$. officinalis showed moderate antiparasitic effects against $T$. cruzi with independence of the salt treatment and stronger salt-dependent effects on the plant parasite $P$. davidi, with the $50 \mathrm{mM}$ $\mathrm{NaCl}$ treatment resulting in the strongest phytomonacidal effect. The hyssop EOs tested here were strong nematicidal agents against $M$. javanica, with these effects also stronger for the 50 
$\mathrm{mM} \mathrm{NaCl}$ treatment. Therefore, a moderate salt treatment $(50 \mathrm{mM} \mathrm{NaCl})$ reduced plant growth and EO yield but increased its biocidal effects on plant parasites ( $P$. davidi and $M$. javanica).

\section{Acknowledgements}

This work has been partially supported by the Tunisian Ministry of Scientific Research and Technology (fellowship to N. Ben Hamida) and grant CTQ2015-64049-C3-1-R (AEI/FEDER,UE).

\section{Disclosure statement}

No potential conflict of interest was reported by the authors.

\section{References}

1. A.Trivellini, M. Lucchesini, R. Maggini, H. Mosadegh, T.S.S.Villamarin, P.Vernieri, A. Mensuali-Sodi and A. Pardossi, Lamiaceae phenols as multifaceted compounds: bioactivity, industrial prospects and role of "positive-stress". Ind. Crop. Prod., 83, 241-254 (2016).

2. F. Bakkali, S. Averbeck, D. Averbeck and M. Idaomar, Biological effects of essential oils. Food Chem. Toxicol., 46, 446-475 (2008).

3. C. Figueiredo, J.G. Barroso, L.G. Pedro and J.J.C. Scheffer, Factors affecting secondary metabolite production in plants: volatile components and essential oils. Flav Fragr. J., 23, 213-226 (2008).

4. F. Fathiazad and S. Hamedeyazdan, Review on Hyssopus officinalis (L.): Composition and biological activities. Afr. J. Pharm. Pharmacol., 5, 1959-1966 (2011).

5. C.E. Ulbricht, Hyssop in: Natural Standard Herb \& Supplement Guide: An Evidence-Based Reference. Elsevier Health Sciences, ISBN 0323291457, 9780323291453, 424-425 (2016).

6. A. Judžentiene, Hyssop (Hyssopus officinalis L.) oils. In: Essential Oils in Food Preservation. Flavor and Safety, Ed. V. Preedy, Academic Press. Pp. 471-479 (2015). 
7. S. Kizil, V. Guler, S. Kirici and M. Turk, Some agronomic characteristics and essential oil composition of Hyssop (Hyssopus officinalis L.) under cultivation conditions. Acta Sci Pol Hortorum Cultus., 15, 193-207 (2016).

8. W. Wang, B. Vinocur and A. Altman, Plant responses to drought, salinity and extreme temperatures: towards genetic engineering for stress tolerance. Planta., 218, 1-14 (2003).

9. P. Shrivastava and R. Kumar, Soil salinity: A serious environmental issue and plant growth promoting bacteria as one of the tools for its alleviation. Saudi J. Biol. Sci., 22, 123-131 (2015).

10. M.L. Binzel and M. Reuveni, Cellular mechanisms of salt tolerance in plant cells. Hortic Rev (Am Soc Hortic Sci)., 16, 33-69 (1994).

11. K. Tsugane, K. Kobayashi, Y. Niwa, Y. Ohba, K. Wada and H. Kobayashi, A recessive Arabidopsis mutant that grows photoautotrophically under salt stress shows enhanced active oxygen detoxification. Plant Cell., 11, 1195-1206 (1999).

12. S. Fatima, A.H. Abad Farooqi and S. Sharma, Physiological and metabolic responses of different genotypes of Cymbopogon martinii and $C$. winterianus to water stress. Plant Growth Regul., 37, 143-149 (2002).

13. A. Khalid, Influence of water stress on growth, essential oil, and chemical composition of herbs (Ocimum sp.). Int. Agrophys., 20, 1-8 (2006).

14. S.A. Petropoulos, D. Dimitra, M.G. Polissiou and H.C. Passam, The effect of water deficit stress on the growth, yield and composition of essential oils of parsley. Sci. Hortic., 15, 393397 (2008).

15. I. Bettaieb, N. Zakhama, W. Aidi Wannes and B. Marzouk, Water deficit effects on Salvia officinalis fatty acids and essential oils composition. Sci. Hortic., 120, 271-275 (2009). 
16. B. Laribi, I. Bettaieb, K. Kouki, A. Sahli, A. Mougou and B. Marzouk, Water deficit effects on caraway (Carum carvi L.) growth, essential oil and fatty acid composition. Ind. Crop. Prod., 30, 372-379 (2009).

17. M. Neffati, J. Sriti, G. Hamdaoui, M.E. Kchouk, B. Marzouk, Salinity impact on fruit yield, essential oil composition and antioxidant activities of Coriandrum sativum fruit extracts. Food Chem., 124, 221-225 (2011).

18. M. Ben Taarit, K. Msaada, K. Hosni, M. Hammami, M.E. Kchouk, B. Marzouk, Plant growth, essential oil yield and composition of sage (Salvia officinalis L.) fruits cultivated under salt stress conditions. Ind. Crop. Prod., 30, 333-337 (2009).

19. O. Jahantigh, F. Najafi, H.N. Badi, R.A. Khavari-Nejad and F. Sanjarian, Essential oil composition of Hyssop (Hyssopus officinalis L.) under salt stress at flowering stage. J. Essent. Oil Res., 28, 458-464 (2016).

20. A. Rosato, F. Maggi, K. Cianfaglione, F. Conti, G. Ciaschetti, R. Rakotosaona, G. Fracchiolla, M.L. Clodoveo, C. Franchini, and F. Corbo, Chemical composition and antibacterial activity of seven uncommon essential oils. J. Essent. Oil Res., 30, 233-243 352 (2018).

21. T. Baj, I. Korona-Glowniak, R. Kowalski and A. Malm, Chemical composition and microbiological evaluation of essential oil from Hyssopus officinalis L. with white and pink flowers. Open Chem., 16, 317-323 (2018).

22. G. Ortiz De Elguea-Culebras, R. Sanchez-Vioque, O. Santana-Méridas, D. herraizPenalver, M. Carmona and M.I. Berruga, In vitro antifungal activity of residues from essential oil industry against Penicillium verrucosum, a common contaminant of ripening cheeses. LWT-Food Sci. Technol., 73, 226-232 (2016). 
Weevil, Sitophilus oryzae (Coleoptera: Curculionidae). J. Essent. Oil Bear. Pl., 20, 937-950 (2017).

24. C. Jianu, I. Golet, C. Misca, A.M. Jianu, G. Pop and A.T. Gruia, Antimicrobial properties and chemical composition of essential oils isolated from six medicinal plants grown in Romania against foodborne pathogens. Rev. Chim. Bucharest., 67, 1056-1061 (2016).

25. N. Stanković, T. Mihajilov-Krstev, B. Zlatkovic, J. Matejic, V. Stankov Jovanovic, B. Kocic and L. Čomic, Comparative Study of Composition, Antioxidant, and Antimicrobial Activities of Essential Oils of Selected Aromatic Plants from Balkan Peninsula. Planta Med., $82,650-661(2016)$.

26. N.I. Guardo, P. Sainz, A. Gonzalez-Coloma, J. Burillo and R.A. Martinez-Diaz, Trypanocidal effects of essential oils from selected medicinal plants. Synergy among the main components. Nat. Prod. Commun., 12, 709-712 (2017).

27. M.F. Andres, A. Gonzalez-Coloma, J. Sanz, J. Burillo and P. Sainz, Nematicidal activity of essential oils: A review. Phytochem. Rev., 11, 371-390 (2012).

28. E.P. Camargo, Phytomonas and other trypanosomatid parasites of plants and fruit. Adv. Parasitol., 42, 29-112 (1999).

29. M. Attias and W. De Souza, Stereological study of isolates of the genus Phytomonas. Acta Microsc., 1, 45-54 (1992).

30. A.D. Uttaro, M. Sanchez-Moreno and F.R. Opperdoes, Genus-specific biochemical markers for Phytomonas spp. Mol. Biochem. Parasitol., 90, 337-342. (1997).

31. M. Dollet, Plant diseases caused by flagellate protozoa (Phytomonas). Ann. Rev. Phytopathol., 22, 115-132 (1984).

32. J.A. Perez-Molina, A. Perez-Ayala, S. Moreno, M.C. Fernandez-Gonzalez, J. Zamora and R. Lopez-Velez, Use of benznidazole to treat chronic Chagas' disease: a systematic review with a meta-analysis. J. Antimicrob. Chemother., 64, 1139-1147 (2009). 
33. A. Gonzalez-Coloma, M. Reina, C. Sáenz, R. Lacret, V.J. Ruiz-Mesia, J. Arán, Sanz and R.A. Martínez-Díaz, Antileishmanial, antitrypanosomal, and cytotoxic screening of ethnopharmacologically selected Peruvian plants. Parasitol. Res., 110, 1381-1392 (2012).

34. C.R. Hoagland and D.I. Arnon, The water-culture method for growing plants without soil. Calif. Agric. (Berkeley), 347, (1950).

35. S. Zaoui, H. Gautier, D. Bancel, G. Chaabani, H. Wasli, M. Lachaal and N. KarrayBouraoui, Antioxidant pool optimization in Carthamus tinctorius L. leaves under different $\mathrm{NaCl}$ levels and treatment durations. Acta Physiol. Plant., 38, 187-198 (2016).

36. E.T. Tsankova, A.N. Konaktchiev and E.M. Genova, Chemical Composition of the Essential Oils of Two Hyssopus officinalis Taxa. J. Essent. Oil Res., 5, 609-611 (1993).

37. R. Adams, Identification of Essential Oil Components by Gas Chromatography/Mass Spectrometry, 4th ed. Allured Publishing Corp, Carol Stream, IL,USA (2007).

38. L.H. Silva and V. Nussenzweig, Sobre una cepa de Trypanosoma cruzi virulenta para o camundongo branco. Folia Clin. Biol., 20, 191-207 (1953).

39. F.J. Postell and R.B. McGhee, Phytomonas davidi (Trypanosomatidae): transmission and ultrastructure. J. Protozool., 22, 10A (1975).

40. S. Alegre-Gomez, P. Sainz, M.F. Simoes, P. Rijo, C. Moiteiro, A. Gonzalez-Coloma and R.A. Martinez Diaz, Antiparasitic activity of diterpenoids against Trypanosoma cruzi. Planta Med., 83, 306-311 (2017).

41. O. Schneider-Orelli, Entomologisches Praktikum: einfuhrung in die land- und forstwirtschaftliche Insektenkunde. Aarau, Sauerlander (1947).

42. Statsoft STATISTICA for Windows (Computer program electronic manual); StatSoft Inc.: Tulsa, OK (1998).

43. J. Rozema and J. Van Diggelen, A comparative study of growth and photosynthesis of four halophytes in response to salinity. Acta Oecol., 12, 673-681(1991). 
44. P.H. Hasegawa, R.A. Bressan, J.K. Zhu and H.J. Bohnert, Plant cellular and molecular responses to high salinity. Annu. Rev. Plant Physiol. Plant Mol. Biol., 51, 463-499 (2000).

45. B.A. Hedge and G.C. Joshi, Mineral salt absorption in saline rice irrigation on growth and photosynthetic pigments of safflower and sunflower plants. Bull. Fac. Sci. Assiut. Univ., 4, 29-39 (1975).

46. K.V. Janardan, K. Murtay, J .Girira and S. Punchanck-Sharais, Salt tolerance of cotton and potential use of saline water for irrigation. Curr. Sci., 45, 334-336 (1976).

47. M. Hamada and A.E. El-Enany, Effect of $\mathrm{NaCl}$ salinity on growth, pigment and mineral element contents, and gas exchange of broad bean and pea plants. Biol. Plant., 36, 75-81 (1994).

48. A. Hajdari, A. Giorgi, G. Beretta, F. Gelmini, S. Buratti, S. Benedetti, A. Merkouri, X. Mala, S. Kabashi, D. Pentimalli, B. Pulaj and B. Mustafa, Phytochemical and sensorial characterization of Hyssopus officinalis subsp. aristatus (godr.) Nyman (Lamiaceae) by GCMS, HPLC-UV-DAD, spectrophotometric assays and e-nose with aid of chemometric techniques. Eur. Food Res. Technol., 244, 1313-1327 (2018).

49. S. Yousefzadeh and H. Naghdi Badi, Changes of essential oil, photosynthetic pigments, and morphological characteristics of hyssop (Hyssopus officinalis L.) at Different Harvesting Time. J. Med. Plants., 16, 79-88 (2017).

50. N. Kara and H. Baydar, Morphogenetic, ontogenetic and diurnal variabilities of hyssop (Hyssopus officinalis L.). Res. Crop., 13, 661-668 (2012).

51. É. Németh-Zambori, P. Rajhart and K. Inotai, Effect of genotype and age on essential oil and total phenolics in hyssop (Hyssopus officinalis L.). J. Appl. Bot. Food. Qual., 90, 25-30 (2017). 
52. H.R. Khazaie, E. Eyshi Rezaie and M. Bannayan, Application times and concentration of humic acid impact on aboveground biomass and oil production of hyssop (Hyssopus officinalis). J. Med. Plant Res., 5, 5148-5154 (2011).

53. A. Moro, A. Zalacain, J.H. De Mendoza and M. Carmona, Effects of agronomic practices on volatile composition of Hyssopus officinalis L. Essential oils. Molecules, 16, 4131-4139 (2011).

54. S. Kindlovits, P. Radacsi, S. Sarosi, K. Inotai, E. Nagy and É. Németh, Effect of weather conditions on the morphology, production and chemical composition of two cultivated medicinal and aromatic species. Eur. J. Hortic. Sci., 79, 76-83 (2014).

55. A. Ozturk, A. Unlukara, A. Ipek and B. Gurbuz, Effects of salt stress and water deficit on plant growth and essential oil content of lemon balm (Melissa officinalis L.). Pak. J. Bot., 36, 787-792 (2004).

56. E.E. Aziz, H. Al-Amier and L.E. Craker, Influence of salt stress on growth and essential oil production in peppermint, pennyroyal, and apple mint. J. Herbs Spices Med. Plants., 14, 77-87 (2008).

57. J. Harrathi, K. Hosni, N. Karray-Bouraoui, H. Attia, B. Marzouk, C. Magne and M. Lachaal, Effect of salt stress on growth, fatty acids and essential oils in safflower (Carthamus tinctorius L.). Acta Physiol. Plant., 34, 129-137 (2012).

58. M. Ben Taarit, K. Msaada, K. Hosni and B. Marzouk, Physiological changes and essential oil composition of clary sage (Salvia sclarea L.) rosette leaves as affected by salinity. Acta Physiol. Plant., 33, 153-162 (2011).

59. H. Greenway and R. Munns, Mechanisms of salt tolerance in non-halophytes. Ann. Rev. Plant Physiol., 31, 149-190 (1980).

60. M.C.G. Vallejo, J.G. Herraiz, M.J. Pérez-Alonso and A. Velasco-Negueruela, Volatile oil of Hyssopus officinalis L. From Spain. J. Essent. Oil Res., 7, 567-568 (1995). 
61. G. Renzini, F. Scazzocchio, M. Lu, G. Mazzanti and G. Salvatore, Antibacterial and cytotoxic activity of Hyssopus officinalis L. oils. J. Essent. Oil Res., 11, 649-654 (1999).

62. G. Mazzanti, L. Battinelli and G. Salvatore, Antimicrobial properties of the linalol-rich essential oil of Hyssopus officinalis L. var decumbens (Lamiaceae). Flavour Frag. J., 13, 289294 (1998).

63. A. Venditti, A.Bianco, C. Frezza, F. Conti, L.M. Bini, C. Giuliani, M. Bramucci, L. Quassinti, S. Damiano, G. Lupidi, D. Beghelli, S. Caterbi, D. Petrelli, L.A. Vitali, F. Papa, G. Caprioli and F. Maggi, Essential oil composition, polar compounds, glandular trichomes and biological activity of Hyssopus officinalis subsp. aristatus (Godr.) Nyman from central Italy. Ind. Crop. Prod., 77, 353-363 (2015).

64. R. Piccaglia, L. Pace and F. Tammaro, Characterization of essential oils from three italian ecotypes of hyssop [Hyssopus officinalis 1. subsp. aristatus (Godron) Briq.]. J. Essent. Oil Res., 11, 693-699 (1999).

65. G. Figueredo, M. Musa Özcan, J.C. Chalchat, Y. Bagci and P. Chalard, Chemical composition of essential oil of Hyssopus officinalis 1. and Origanum acutidens. J. Essent. Oil Bear. Pl., 15, 300-306 (2012).

66. H. Ozer, M. Sokmen, M. Gulluce, A. Adiguzel, H. Kilic, F. Sahin, A. Soekmen and O Baris, In-vitro antimicrobial and antioxidant activities of the essential oils and methanol extracts of Hyssopus officinalis L. ssp. angustifolius. Ital. J. Food Sci., 18, 73-83 (2006).

67. J.C. Chalchat, D. Adamovic and M.S. Gorunovic, Composition of oils of three cultivated forms of Hyssopus officinalis endemic in Yugoslavia: F. albus Alef., f. cyaneus Alef. and f. ruber Mill. J. Essent. Oil Res., 13, 419-421 (2001).

68. O. Baatour, R. Kaddour, W. Aidi-Wannes, M. Lachaal and B. Marzouk, Salt effects on the growth, mineral nutrition, essential oil yield and composition of marjoram (Origanum majorana). Acta Physiol. Plant., 32, 45-51 (2010). 
69. A.K. Khalid and M.R. Shedeed, GC-MS analyses of black cumin essential oil produces with sodium chloride. Int. Food Res. J., 23, 832-836 (2016).

70. P. Sartorelli, J.S. Santana, R.C. Guadagnin, J.H.G. Lago, E.G. Pinto, A.G. Tempone, H.A. Stefani, M.G. Soares and A.M. Da Silva, In vitro trypanocidal evaluation of pinane derivatives from essential oils of ripe fruits from Schinus terebinthifolius raddi (Anacardiaceae). Quim. Nova., 35, 743-747 (2012).

71. S.L. Ngahang Kamte, F. Ranjbarian, K. Cianfaglione, S. Sut, S. Dall'acqua, M. Bruno, F.H. Afshar, R. Iannarelli, G. Benelli, L. Cappellacci, A. Hofer, F. Maggi and R. Petrelli, Identification of highly effective antitrypanosomal compounds in essential oils from the Apiaceae family. Ecotoxicol. Environ. Saf., 156, 154-165 (2018).

72. S.L. Stokes, R.A. Cole, M.P. Rangelova, W.A. Haber and W.N. Setzer, Cruzain inhibitory activity of the leaf essential oil from an undescribed species of Eugenia from Monteverde, Costa Rica. Nat. Prod. Commun., 2, 1211-1213 (2007).

73. W.N. Setzer, S.L. Stokes, A.F. Penton, S. Takaku, W.A. Haber, E. Hansell, C.R. Caffrey, and J.H. Mckerrow, Cruzain inhibitory activity of leaf essential oils of neotropical Lauraceae and essential oil components. Nat. Prod. Commun., 2, 1203-1210 (2007).

74. M.W. Biavatti, P.C. Vieira, M.F.G.F. Da Silva, J.B. Fernandes, S. Albuquerque, Magalhaes and F.C. Pagnocca, Chemistry and bioactivity of Raulinoa echinata Cowan, an endemic Brazilian Rutaceae species. Phytomedicine., 8, 121-124 (2001).

75. D. J. Chitwood, Phytochemical based strategies for nematode control. Annu Rev Phytopathol., 40, 221-249 (2002).

76. G. Ortiz de Elguea-Culebras, R. Sánchez-Vioque, M.I. Berruga, D. Herraiz-Peñalver, A. González-Coloma, M.F. Andrés and O. Santana-Méridas, Biocidal potential and chemical composition of industrial essential oils from Hyssopus officinalis, Lavandula x intermedia var. super, and Santolina chamaecyparissus. Chem. Biodivers., 15, e1700313(2018). 
510 77. G. Benelli, R. Pavela, A. Canale, K. Cianfaglione, G. Ciaschetti, F. Conti, M. Nicoletti, S.

511 Senthil-Nathan, H. Mehlhorn and F. Maggi, Acute larvicidal toxicity of five essential oils

512 (Pinus nigra, Hyssopus officinalis, Satureja montana, Aloysia citrodora and Pelargonium

513 graveolens) against the filariasis vector Culex quinquefasciatus: synergistic and antagonistic

514 effects. Parasitol. Int., 66, 166-171 (2017).

515 78. J.S. Kang, E. Kim, S.H. LEE and I. Park, Inhibition of acetylcholinesterases of the

516 pinewood nematode, Bursaphelenchus xylophilus, by phytochemicals from plant essential

517 oils. Pestic. Biochem. Physiol., 105, 50-56 (2013).

518 79. M.C. Navarro-Moll, M.C. Romero, M.P. Montilla and A.Valero. In vitro and in vivo

519 activity of three sesquiterpenes against L3 larvae of Anisakis type I. Exp. Parasitol., 127, 405-

520408 (2011). 

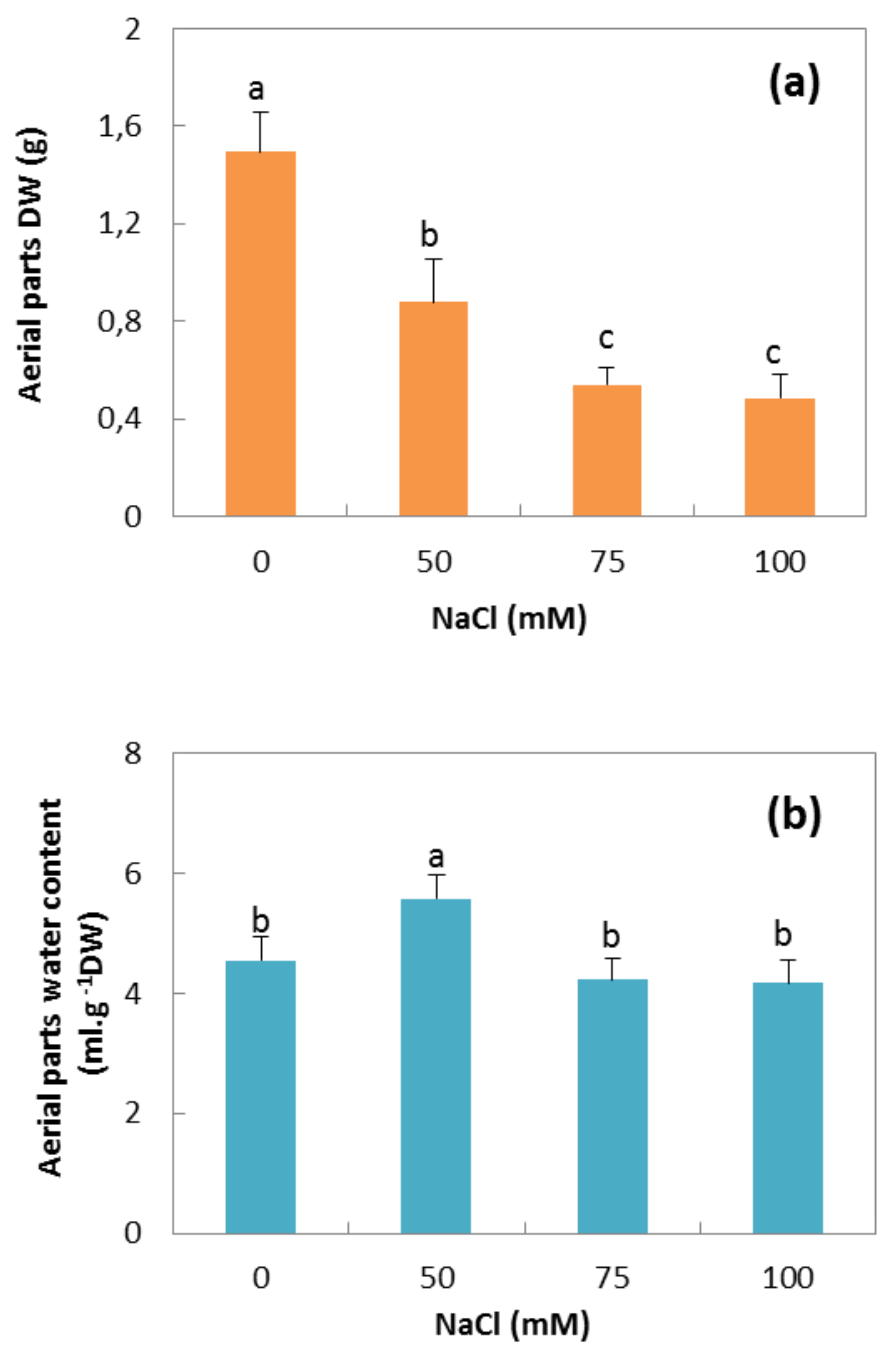

Figure 1. Effect of salinity on dry weight (DW) of aerial parts (a) and water content (b) in hyssop plants grown in the presence of $0,50,75$ and $100 \mathrm{mM} \mathrm{NaCl}$. Bars represent mean values of six replicates \pm standard error. Different letters indicate significant differences according to Duncan's test at $\mathrm{P}<0.05$. 

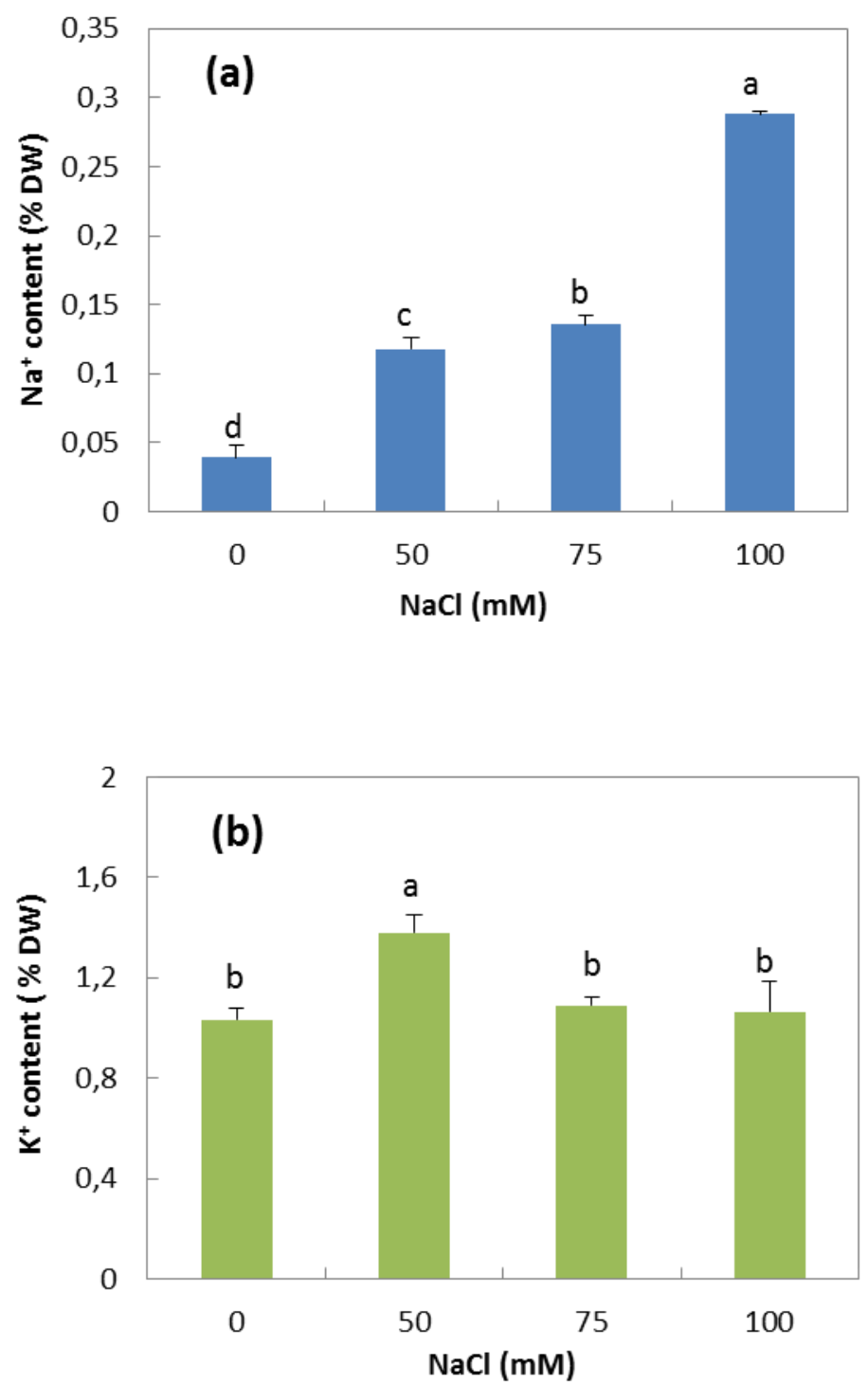

Figure 2. Effect of salinity on sodium $\left(\mathrm{Na}^{+}\right)$(a) and potassium $\left(\mathrm{K}^{+}\right)(\mathrm{b})$ contents in the aerial parts of hyssop plants grown in the presence of $0,50,75$ and $100 \mathrm{mM} \mathrm{NaCl}$. Bars represent mean values of six replicates \pm standard error. Different letters indicate significant differences according to Duncan's test at $\mathrm{P}<0.05$. 


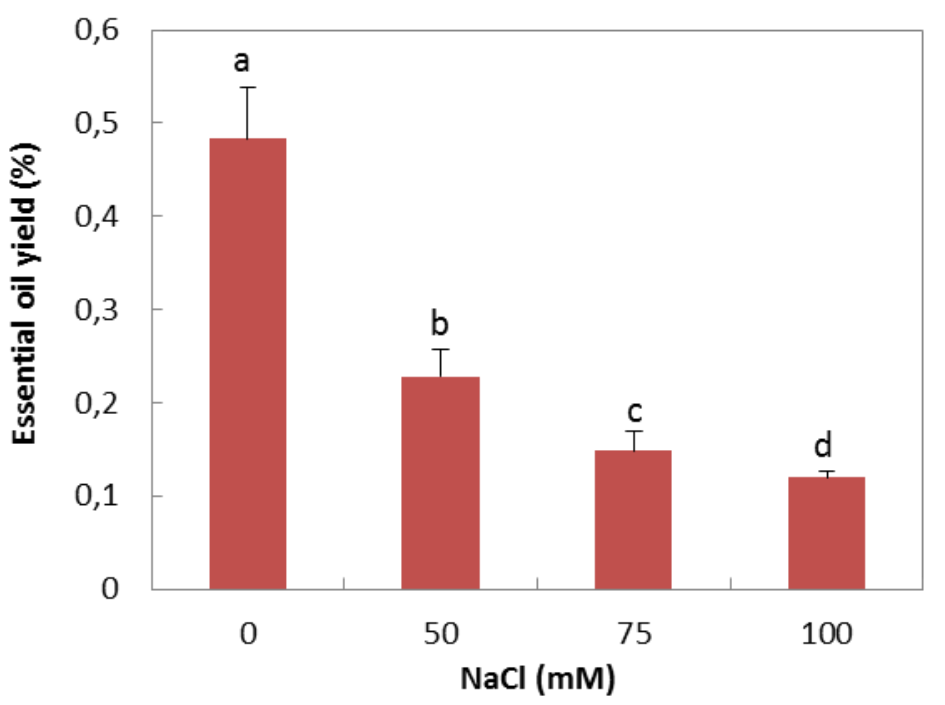

Figure 3. Effect of salinity on essential oil yield of hyssop aerial parts in the presence of 0 , 50, 75 and $100 \mathrm{mM} \mathrm{NaCl}$. Data with different letters are significantly different according to Duncan's test at $\mathrm{P}<0.05$ (means of three replicates \pm standard deviation). 
Table 1. Essential oil composition (\% peak area) of Hyssopus officinalis L. aerial parts under different $\mathrm{NaCl}$ concentrations (0, 50,75 and $100 \mathrm{mM})$ at vegetative stage.

\begin{tabular}{|c|c|c|c|c|c|c|c|c|}
\hline \multirow[b]{2}{*}{ Compounds $\dagger$} & \multirow[b]{2}{*}{ RRI } & \multicolumn{4}{|c|}{$\mathrm{NaCl}(\mathrm{mM})$} & \multirow[b]{2}{*}{ d.f } & \multirow[b]{2}{*}{$F$} & \multirow[b]{2}{*}{$P$} \\
\hline & & 0 & 50 & 75 & 100 & & & \\
\hline$\alpha$-Pinene & 936 & $0.36 \pm 0.05^{\mathrm{a}}$ & $0.24 \pm 0.01^{\mathrm{b}}$ & $0.22 \pm 0.00^{\mathrm{b}}$ & $0.09 \pm 0.21^{\mathrm{c}}$ & 3 & 19.84 & $0.000 * * *$ \\
\hline Sabinene & 973 & $1.37 \pm 0.07^{\mathrm{a}}$ & $1.04 \pm 0.02^{\mathrm{b}}$ & $0.97 \pm 0.01^{\mathrm{c}}$ & $0.79 \pm 0.01^{\mathrm{d}}$ & 3 & 684.00 & $0.000 * * *$ \\
\hline$\beta$-Pinene & 978 & $8.16 \pm 0.42^{\mathrm{a}}$ & $6.5 \pm 0.25^{b}$ & $5.93 \pm 0.02^{c}$ & $5.07 \pm 0.09^{d}$ & 3 & 508.13 & $0.000 * * *$ \\
\hline$\beta$-Myrcene & 987 & $1.34 \pm 0.15^{\mathrm{a}}$ & $1.00 \pm 0.01^{\mathrm{b}}$ & $0.88 \pm 0.01^{\mathrm{c}}$ & $0.86 \pm 0.01^{\mathrm{c}}$ & 3 & 164.29 & $0.000 * * *$ \\
\hline$\beta$-Phellandrene & 1024 & $3.08 \pm 0.17^{\mathrm{a}}$ & $2.67 \pm 0.07^{b}$ & $2.03 \pm 0.00^{\mathrm{d}}$ & $2.58 \pm 0.00^{\mathrm{c}}$ & 3 & 386.34 & $0.000 * * *$ \\
\hline Linalool & 1086 & $0.49 \pm 0.09^{\mathrm{a}}$ & $0.34 \pm 0.05^{\mathrm{b}}$ & $0.34 \pm 0.02^{b}$ & $0.38 \pm 0.09^{b}$ & 3 & 19.18 & $0.000 * * *$ \\
\hline Neoalloocimene & 1113 & $2.30 \pm 0.14^{\mathrm{d}}$ & $2.67 \pm 0.00^{\mathrm{c}}$ & $3.00 \pm 0.02^{\mathrm{a}}$ & $2.94 \pm 0.01^{\mathrm{b}}$ & 3 & 390.66 & $0.000 * * *$ \\
\hline Pinocarvone & 1137 & $15.99 \pm 0.55^{\mathrm{a}}$ & $14.91 \pm 0.40^{\mathrm{b}}$ & $13.86 \pm 0.12^{\mathrm{c}}$ & $12.45 \pm 0.05^{\mathrm{d}}$ & 3 & 356.00 & $0.000 * * *$ \\
\hline Isopinocamphone & 1151 & $27.70 \pm 1.08^{\mathrm{a}}$ & $27.18 \pm 0.73^{b}$ & $26.62 \pm 0.07^{\mathrm{c}}$ & $27.30 \pm 0.4^{\mathrm{ab}}$ & 3 & 8.43 & $0.002 * *$ \\
\hline Myrtenyl acetate & 1313 & $4.70 \pm 0.09^{b}$ & $4.66 \pm 0.10^{\mathrm{b}}$ & $4.95 \pm 0.05^{\mathrm{a}}$ & $4.66 \pm 0.07^{\mathrm{b}}$ & 3 & 57.13 & $0.000 * * *$ \\
\hline Bicycloelemene & 1338 & $2.44 \pm 0.35^{\mathrm{c}}$ & $2.76 \pm 0.21^{\mathrm{b}}$ & $3.04 \pm 0.02^{\mathrm{a}}$ & $2.95 \pm 0.01^{\mathrm{a}}$ & 3 & 31.19 & $0.000 * * *$ \\
\hline$\beta$-Cubebene & 1390 & $0.39 \pm 0.06^{\mathrm{b}}$ & $0.40 \pm 0.04^{\mathrm{ab}}$ & $0.42 \pm 0.00^{\mathrm{a}}$ & $0.41 \pm 0.01^{\mathrm{ab}}$ & 3 & 3.05 & $0.004 *$ \\
\hline$\alpha$-Gurjunene & 1413 & $0.57 \pm 0.02^{\mathrm{c}}$ & $0.61 \pm 0.01^{\mathrm{b}}$ & $0.68 \pm 0.00^{\mathrm{a}}$ & $0.68 \pm 0.00^{\mathrm{a}}$ & 3 & 293.40 & $0.000 * * *$ \\
\hline trans-Caryophyllene & 1422 & $3.24 \pm 0.25^{\mathrm{c}}$ & $3.94 \pm 0.05^{\mathrm{b}}$ & $3.94 \pm 0.01^{\mathrm{b}}$ & $4.49 \pm 0.05^{\mathrm{a}}$ & 3 & 290.63 & $0.000 * * *$ \\
\hline$\alpha$-Humulene & 1455 & $0.69 \pm 0.15^{\mathrm{c}}$ & $0.84 \pm 0.07^{\mathrm{b}}$ & $0.87 \pm 0.01^{\mathrm{b}}$ & $0.96 \pm 0.02^{\mathrm{a}}$ & 3 & 32.44 & $0.000 * * *$ \\
\hline Germacrene-D & 1479 & $7.22 \pm 0.26^{\mathrm{c}}$ & $7.48 \pm 0.09^{\mathrm{b}}$ & $8.12 \pm 0.06^{\mathrm{a}}$ & $8.06 \pm 0.06^{\mathrm{a}}$ & 3 & 172.80 & $0.000 * * *$ \\
\hline Bicyclogermacrene & 1494 & $3.68 \pm 0.09^{c}$ & $4.14 \pm 0.11^{\mathrm{b}}$ & $4.51 \pm 0.07^{\mathrm{a}}$ & $4.56 \pm 0.00^{\mathrm{a}}$ & 3 & 31.19 & $0.000 * * *$ \\
\hline Elemol & 1541 & $12.25 \pm 0.95^{\mathrm{c}}$ & $13.13 \pm 0.20^{\mathrm{b}}$ & $14.41 \pm 0.16^{\mathrm{a}}$ & $13.30 \pm 0.09^{\mathrm{b}}$ & 3 & 58.94 & $0.000 * * *$ \\
\hline \multicolumn{9}{|c|}{ Grouped compounds } \\
\hline Monoterpene hydrocarbons & & $16.61 \pm 0.73^{\mathrm{a}}$ & $14.12 \pm 0.37^{\mathrm{b}}$ & $13.03 \pm 0.05^{\mathrm{c}}$ & $12.33 \pm 0.09^{\mathrm{d}}$ & & & \\
\hline Oxygenated monoterpenes & & $44.18 \pm 1.71^{\mathrm{a}}$ & $42.43 \pm 1.08^{\mathrm{b}}$ & $40.82 \pm 0.22^{\mathrm{c}}$ & $40.13 \pm 0.10^{\mathrm{c}}$ & & & \\
\hline Sesquiterpene hydrocarbons & & $18.23 \pm 1.18^{\mathrm{d}}$ & $20.17 \pm 0.16^{\mathrm{c}}$ & $21.58 \pm 0.12^{\mathrm{b}}$ & $22.11 \pm 0.14^{\mathrm{a}}$ & & & \\
\hline Oxygenated sesquiterpenes & & $12.25 \pm 0.95^{\mathrm{c}}$ & $13.13 \pm 0.20^{\mathrm{b}}$ & $14.41 \pm 0.16^{\mathrm{a}}$ & $13.30 \pm 0.09^{\mathrm{b}}$ & & & \\
\hline Other & & $4.70 \pm 0.09^{b}$ & $4.66 \pm 0.10^{\mathrm{b}}$ & $4.95 \pm 0.05^{\mathrm{a}}$ & $4.66 \pm 0.07^{\mathrm{b}}$ & & & \\
\hline Total identified & & $95.97 \pm 8.24^{\mathrm{a}}$ & $94.51 \pm 9.67^{\mathrm{c}}$ & $94.79 \pm 10.25^{\mathrm{b}}$ & $\mathbf{9 2 . 5 3} \pm 9.83^{\mathrm{d}}$ & & & \\
\hline
\end{tabular}

$\uparrow$ Order of elution in apolar column (TRB-5). Volatile compounds percentages in the same line with different superscript (a-d) are significantly different at $\mathrm{P}<0.05 ; * \mathrm{P}<0.05$; $* * \mathrm{P}<0.01 ; * * * \mathrm{P}<0.001$ 
Table 2. Activity of Hyssopus officinalis L. essential oils (EO Ho0, EO Ho50, EO Ho75 and EO Ho100) against epimastigotes of Trypanosoma cruzi and promastigotes of Phytomonas davidi. Nifurtimox was included as reference drug.

\begin{tabular}{|c|c|c|c|c|c|c|}
\hline \multirow[t]{2}{*}{ EO } & & \multicolumn{4}{|c|}{ Concentration $(\mu \mathrm{g} / \mathrm{mL})$} & \multirow{2}{*}{$\begin{array}{c}\mathrm{EC}_{50^{\mathrm{a}}} \\
(\mu \mathrm{g} / \mathrm{mL})\end{array}$} \\
\hline & & 1 & $\mathbf{1 0}$ & 100 & 200 & \\
\hline \multirow[t]{2}{*}{ EO Ho0 } & T. cruzi & $0.6 \pm 0.1$ & $0.2 \pm 0.1$ & $43.1 \pm 4.2$ & 100 & 110.0 \\
\hline & P. davidi & $9.2 \pm 0.3$ & $30.4 \pm 2.9$ & $39.2 \pm 4.2$ & 100 & $100-160$ \\
\hline \multirow[t]{2}{*}{ EO Ho50 } & T. cruzi & 0 & 0 & $53.6 \pm 13.0$ & 100 & $\sim 100$ \\
\hline & P. davidi & 0 & 0 & $97.1 \pm 0.5$ & 100 & $10-100$ \\
\hline \multirow[t]{2}{*}{ EO Ho75 } & T. cruzi & 0 & $9.7 \pm 0.8$ & $43.7 \pm 9.0$ & 100 & 137.1 \\
\hline & P. davidi & 0 & 0 & $58.0 \pm 6.3$ & 100 & $\sim 100$ \\
\hline \multirow[t]{2}{*}{ EO Ho100 } & T. cruzi & $1.5 \pm 0.1$ & $0.2 \pm 0.1$ & $45.7 \pm 2.2$ & 100 & 164.4 \\
\hline & P. davidi & 0 & 0 & $78.1 \pm 3.0$ & 100 & $10-100$ \\
\hline Nifurtimox & T. cruzi & $7.9 \pm 0.7$ & $87.9 \pm 4.7$ & 100 & 100 & 4.7 \\
\hline
\end{tabular}

Data are expressed as percentage of growth inhibition (means of three replicates \pm standard error). EO Ho0: control, EO Ho50: essential oil treated with $50 \mathrm{mM} \mathrm{NaCl}$, EO Ho75: essential oil treated with 75 $\mathrm{mM} \mathrm{NaCl}$, EO Ho100: essential oil treated with $100 \mathrm{mM} \mathrm{NaCl}$.

${ }^{a}$ Estimated $\mathrm{EC}_{50}$ values (dose at which the growth of the culture is reduced by $50 \%$ ). 
Table 3. Effects of Hyssopus officinalis essential oils (EO Ho0: control, EO Ho50: essential oil treated with $50 \mathrm{mM} \mathrm{NaCl}$, EO Ho75: essential oil treated with $75 \mathrm{mM}$ $\mathrm{NaCl}$, EO Ho100: essential oil treated with $100 \mathrm{mM} \mathrm{NaCl}$ ) on mortality of Meloidogyne javanica second stage juveniles (J2).

\begin{tabular}{ccc}
\hline EO & $\boldsymbol{\mu g} / \boldsymbol{\mu l}$ & $\mathbf{J 2}^{2}$ mortality $(\%)^{\mathbf{a}}$ \\
\hline Ho0 & 1 & $81.79 \pm 3.63$ \\
& 0.5 & $0.35 \pm 1.05$ \\
Ho50 & 0.25 & 0 \\
& 1 & $88.73 \pm 4.61$ \\
Ho75 & 0.5 & $5.44 \pm 1.29$ \\
& 0.25 & $1.02 \pm 1.0$ \\
& 1 & $73.29 \pm 4.09$ \\
Ho100 & 0.5 & $2.76 \pm 1,71$ \\
& 0.25 & 0 \\
& 1 & $65.71 \pm 1.74$ \\
& 0.5 & $9.48 \pm 1.64$ \\
& 0.25 & $0.75 \pm 0.82$ \\
\hline
\end{tabular}

${ }^{\text {a }}$ Values $(\%)$ are means of four replicates \pm standard error, corrected according to SchneidereOrelli's formula (Schneider-Orelli, 1947). 
Table 4. Effects of Hyssopus officinalis essential oils (EO Ho0: control, EO Ho50: essential oil treated with $50 \mathrm{mM} \mathrm{NaCl}$, EO Ho75: essential oil treated with $75 \mathrm{mM}$ $\mathrm{NaCl}$, EO Ho100: essential oil treated with $100 \mathrm{mM} \mathrm{NaCl}$ ) on mortality of Meloidogyne javanica second stage juveniles (J2).

\begin{tabular}{ccc}
\hline EO & $\boldsymbol{\mu g} / \boldsymbol{\mu l}$ & $\mathbf{J 2}$ mortality $(\%)^{\mathrm{a}}$ \\
\hline Ho0 & 1 & $81.79 \pm 3.63$ \\
& 0.5 & $0.35 \pm 1.05$ \\
Ho50 & 0.25 & 0 \\
& 1 & $88.73 \pm 4.61$ \\
Ho75 & 0.5 & $5.44 \pm 1.29$ \\
& 0.25 & $1.02 \pm 1.0$ \\
& 1 & $73.29 \pm 4.09$ \\
Ho100 & 0.5 & $2.76 \pm 1,71$ \\
& 0.25 & 0 \\
& 1 & $65.71 \pm 1.74$ \\
& 0.5 & $9.48 \pm 1.64$ \\
& 0.25 & $0.75 \pm 0.82$ \\
\hline
\end{tabular}

${ }^{\text {a }}$ Corrected according to Scheider-Orelli's formula. Values are means of four replicates. 